\section{DN THE SPECTROSCOPE AND ITS APPLICATIONS}

I.

$W^{E}$ E now anproach Newton's great discovery, which is this:- " " he light of the sun consists of rays aiferently refrangible;" that is to say, if we take a beam of sunlight, and make it pass through a prism, we shall get colours of different refrangibility. We see then that if, instead of two coloured beams, we pass one of perfectly white light through the prism, the action of the prism is at once to turn that beam into a beautifully coloured band, which will remind you of a rainbow. It was this which Newton did in a dark room, which led him to his important discovery. White light is compounded of light of different degrees of refrancibility. But how is it possible to show the truth of Newton's assertion that white light is compounded of these different colours? We can do so by simply placing in the path of the coloured beam which you see passing through the room, another prism placed in a contrary direction, as shown in Fig. ro; you see in a moment that we get back white light; for the second prism exactly neutralises the effect caused by the first, and the ray proceeds as if nothing had happened.

Possibly you may ask, is it true that white light is built up of all colours? That question can be answered to a reutain extent by an experiment of a different order. I

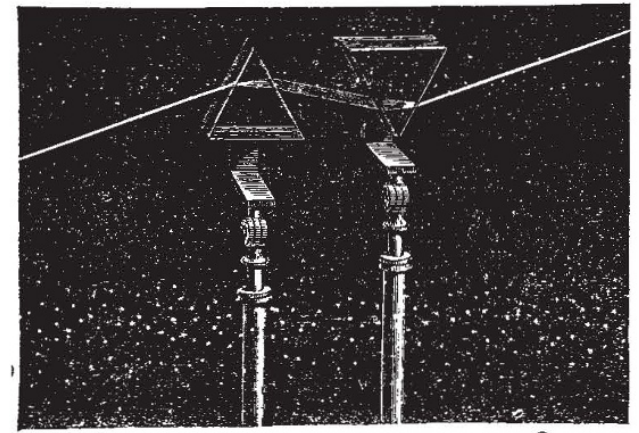

F1G. ro - Rec smposition of wh te light by means of a seco:d prism.

a disc, divided into sections and coloured with the principal colnurs of the spectrum as shown in Fig. II be taken, and if it be true that the idea of white light is simply an idea built up by the eyc, because we have all these multitudes of light waves perpetually pouring into it with a velocity that is very much greater than anything which can be translated into words, surely we should get something like this effect also if we were able, by rapidly rotating this screen, to obtain a more or less perfect substitute for white light. The colcured disc being made to rotate rapidly, you see we obtain somet'ing like an approximation to white light, though the white colour does not come out so clearly as it might do. Now I am very anxious that you should see that this is really an effect due to the flowing in of light from different parts of that wheel into the eye, and so forming this compound impression, which is conveyed to the brain; and so if instead of illuminating the disc continuously by the electric lamp, or by sunlight, it is illuminated intermittently, by an electric spark, you would see that although the disc is rotating rapidly all the time, each separate colour is now discernible, and the disc appears to stand still. The reason of this difference is, that in one case the rotation of the wheel builds up a compound image in the eye, and in the other case it cannot do so, because the flash of the light is much more rapid and instantaneous than the rotation of the wheel

There is one more experiment which can be easily made, to show that all the beautiful colour which we get in nature is really reflected after all, and that if our sun- light, instead of being polychromatic-that is to say, compounded of all these beautiful colours-were monochromatic, or of one colour only, the whole expanse of creation would put on a very different appearance from what it does. If, instead of illuminating a diagram, the letters of which are of different bright colours, by the white light of the electric lamp, we illuminate it by a light that only contains one colour-by the yellow light of sodium, for instance, and then look at the diagram, you will see that snme of the letters upon it are almost invisible, whilst others are very clear, the yellow light only allowing a difference to be seen of more or less depth of shade, there being no difference in colour. But when we allow the polychromatic light from the lamp, or as we get it from the sun, to shine upon the diagram, you at once see that all these letters are of different colours, and burst out, as it were, into beauty, This experiment feebly indicates the advantage we possess in living in a universe lit by white or polychromatic light, instead of light which is merely blue, or yellow, or any other single colour.

Hitherto we have spoken only of refraction. I now introduce the word dispersion, which represents simply a measure of different refractions, or the difference between the bending of the red and the violet rays of light. In an ordinary spectrum the difference brtween the red and the

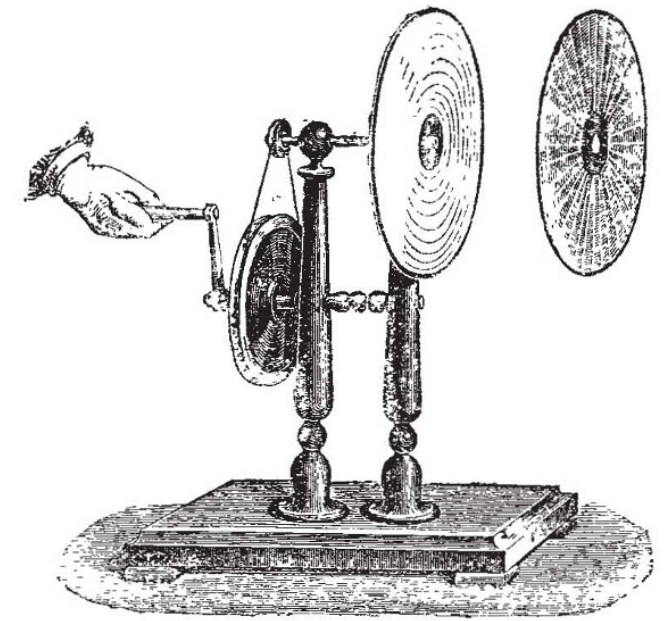

FIG. Ir.-Recomposiion of white light by means of a 1 pidly revolving disc coloured in sections

violet is the difference of the refraction of those two colours by the prism, and the angle which the red, or yellow, or other colour forms with the original path of the compound-beam is called the angle of deviation.

There is one other consideration which we owe to Newton. In his very first experiments, that great philosopher discovered that the quality of the spectrum depended very much on the following consideration :- If I wish to get the best possible effect out of a prism and the purest possible spectrum, I have so to arrange it that the particular ray which I wish to observe, whether the yellow, the blue, the green, or any other, leaves that prism at exactly the same angle as the incident compound ray falls on it. This angle is termed the angle of minimum deviation.

The two things, therefore, of greatest importance in this subject which we owe to Newton are, first, the explanation of the dispersive power of the prism; and next, tire pointing out the extreme importance of arranging the prism, so that if we want to observe any particular part of the spectrum, the rays constituting that part of the spectrum should leave the prism at the same angle as the white light falls on it.

It is very curious, however, that Newton, although he made many experiments on prisms, really omitted one of the most important points, which you will see carefully 
arranged for in every one of the spectroscopes used at the present day. And here again we get an idea of the enormous patience which is necessary in these matters, for we had to wait a century and a quarter before the next essential point was hit upon in the construction of a spectroscope. Newton made a round hole in a shutter for his experiments, but we now know that he ought not to have done that; he ought to have made a slit. But this did not come out until I8o2, when Dr. Wollaston, by merely using a slit instead of a round hole, made a tremendous step in advance. You will see the importance of this in a moment. If we take a cylindrical beam of sunlight and put a prism in the path of the beam, we observe that the spectrum is not a pure one ; but if we change the round hole for a slit, we obtain a spectrum of the greatest purity; the red, blue, green, and violet, instead of overlapping and destroying the beauty of the spectrum, show distinctly as simple colours, each one speaking for itself on the screen. By using this narrow slit instead of the round hole which Newton made in the shutter, we got the first idea of the tremendous importance of spectrum analysis; for no sooner had Dr. Wollaston examined the sunlight with the new arrangement, as Newton had done a century and a quarter before with the old one, than he found out that it was not at all as Newton had represented it. Newton told us in fact that the sunlight was continuous, that is to say, that the spectrunt was one in which there was no break in the light which flowed out to every part of the spectrum, from the extreme red to the violet. When Dr. Wollaston tried the slit he found, however, that the spectrum, instead of being that rainbow band of light which you have seen, was really broken by a succession of fine-beautifully fine-black lines.

These lines were observed by Dr. Wollaston, but it was not till 1814 that we find them mapped out with the greatest care, to the number of 576 , by a German optician named Fraunhofer; hence they are termed "Fraunhofer lines," the principal ones being lettered A, B, C, \&c.

If we say, then, that spectroscopic inquiry dawned with Newton, certainly the sun began to rise with Fraunhofer, for he, no longer content with getting a sunbeam through this slit, and finding out and measuring with most admirable accuracy these 576 lines in that band of colour, turned his telescope to the moon and the planets, and the different stars; and he discovered that, in the case of the stars, the positions of the lines varied considerably from those they occupied in the spectrum of the sun; and this is one of the most important discoveries which has been made during the present century in these matters. In-
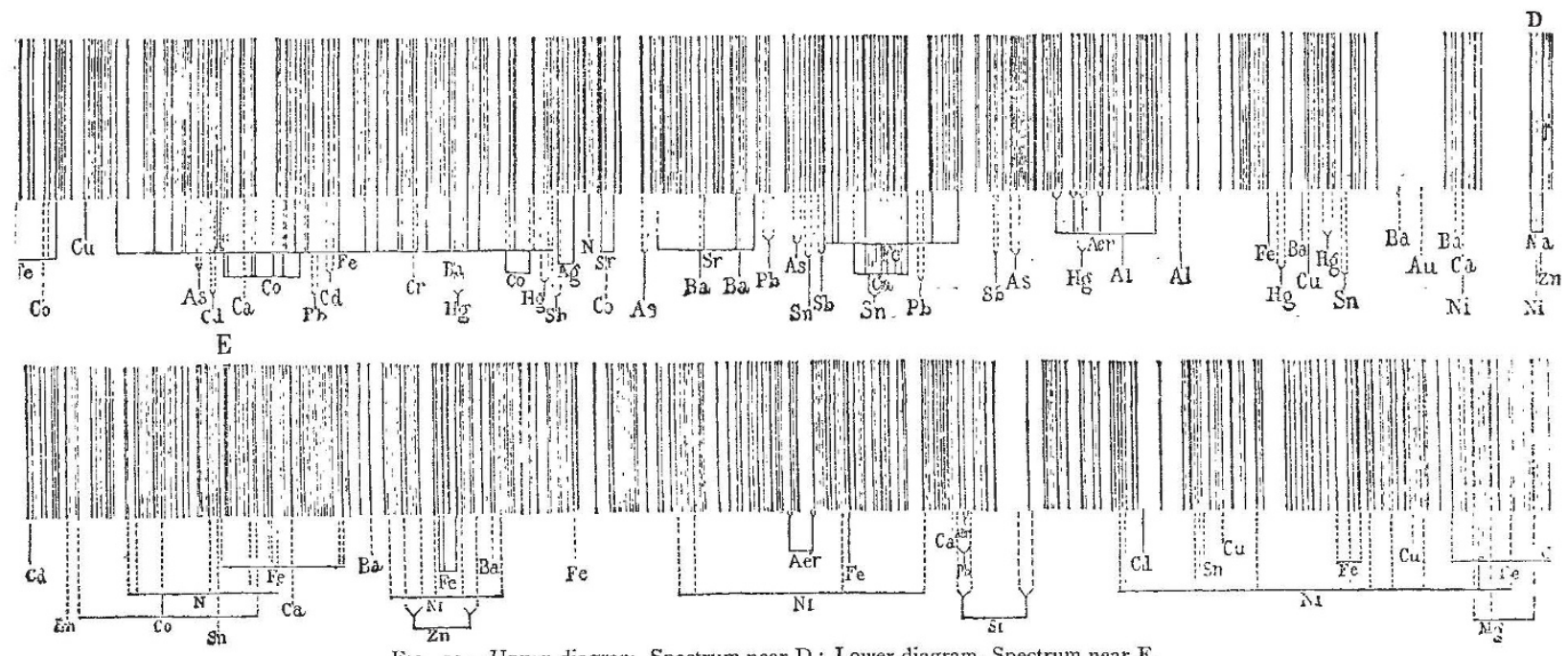

Fig. 12.-Upper diagram, Spectrum near D : Lower diagram, Spectrum near E.

deed, it is the foundation of very much of the later more detailed work.

The solar spectrum then, as we have said, far from being continuous, is crossed by an almost innumerable number of dark lines, some being fine and others thicker and blacker. Fig. 12 shows a small portion of the spectrum in the yellow and green. Other observers, such as Kirchhoff, Thalén, and Angström, have worked at these dark lines, and have drawn most beautiful and elaborate maps, showing at least 2,000 lines of various thicknesses.

We have now to pass on from 181.2 to the year 1830 , when Mr. Simms, an optician of world-wide reputation, made another very important improvement in the spectroscope. Instead of merely using a prism and observing the slit with the naked eye, he placed a lens in front of the prism, so arranged that the slit was in the focus of the lens. The light which is allowed to pass through the slit is thus turned into a cylindrical beam, and thus travels through the prism; then, instead of having merely the eye to observe the spectrum, there is another lens which grasps the circular beam and compels it to throw an image of the slit, which may be magnified at pleasure. The very great importance of this construction is at once obvious, if you think for one moment of the figure showing the lines in the solar spectrum. We now know, and it is not too early to place this before you, that these black lines indicate regions in the spectrum where there is no light. If the light is perfectly continuous, so that every ray of light is enabled to register itself at the end of the telescope, by painting an image of the slit, you will get a continuous spectrum ; but supposing, for instance, that the whole of the yellow light were absent, it is clear that the spectroscope, if it does its duty well, will give you blackness where the yellow light is absent. We do not find that the whole of any particular colour is absent, but here and there, scattered over all the colours, there are these places where the rays of light do not come to tell their story. This is the explanation of the Fraunhofer lines in the solar spectrum. In the light which we get from the sun, certain of the rays which we may suppose ought to come to us, do not come, and we get no news from them. We do get news of some of the other rays, which show us the various shades of blue, of green, and so un; but here and there a ray, which possibly might have come if it were not better employed, does not come, and therefore the image of the slit cannot be painted.

I am glad to say that we know a little more about these lines than we did some years ago. You may imagine the enormous mystery - the wonderful reverence almost-with which this question of the Fraunhofer lines 
was approached, until they were thoroughly understood; and recollect that we owe the discovery of them-by which we are enabled now to determine the pressures acting in the atmospheres of the most distant starssimply to the fact that Dr. Wollaston, instead of drilling a round hole, used a slit ; and to the other additional fact, that Mr. Simms, instead of using that slit with a mere prism, used a lens and made the beam parallel, and then allowed that parallel beam, after it had passed through the prism, to pass into another telescope, and form an image of the slit. You see how closely connected are the grandest discoveries with the skill and suggestiveness of those who supply different instruments for our use.

Now I must ask you to come back again to the prism. $I$ have already told you that dispersion is the measure of the difference of the refrangibilities. If we take a prism which appears like an ordinary one, but really is composed of several layers of different kinds of glass, and pass an ordinary beam of light through it, it will be differently acted upon by the various layers, and we shall get a difference in the spectra. We have here, in fact, three distinct spectra, showing that there is something in the different layers of which this prism is composed which turns the light out of its path, and which disperses it more in some cases than it does in others. The cause of this is the density of the glass composing each layer: some kinds of glass are nearly twice as heavty as others, and fortunately we are not limited to glass, for if we were we should not be able to go so far in these inquiries as we do. The prism in reality consists of three separate pieces of glass of different density, and it may be seen that the three spectra obtained are differently refracted. It is a very natural conclusion that the heavier and denser glass should have a stronger action on the light than the lighter glass has. So that, in these inquiries, if we want to get great dispersion, not only must we use heavy glass, but we leave glass behind altogether, as mongst the liquids we firid some which give even a greater dispersion than the densest glass. If a beam is passed through a hollow prism of glass filled with bisuiphide of carbon, the spectrum obtained is much longer than that produced by the densest flint glass we can get. But there is another consideration to be borne in mind. The dispersive power and refractive power not only depend upon the density of the glass, but on the angles of the prism. If a beam of light is sent through two prisms of unequal angles the effect is extremely distinct. Thus, if we take one prism with an angle of $20^{\circ}$ and another with an angle of $60^{\circ}$, the larger angle gives us a much greater deviation and dispersion; therefore, we not only have density to help us, but we have also the angle of the prism.

And now let us go on to a third important point in the matter. We are not limited to one prism if we wish to get a great amount of dispersion; if you will think the matter over, you will see that there is no good reason why we should not employ two, and then you will find that the dispersion will be considerable. So you see, first, we have a single prism of a dense substance; by increasing the angle we get increased dispersion, and then we get it still further increased by adding another prism, and so we might go on, adding prism after prism, until we get to any number of prisms arranged in the best possible manner for the light to be successively dispersed by each of them. First of all, you have the dispersive power of glass, then you have the angle of the prism, and then you have a number of prisms, all of them capable of being so arranged that we can make them all useful in these inquiries, until at last we get a dispersion of such an enormous amount that the spectrum of the sun, as mapped by Kirchhoff and Bünsen, is several yards in length, although it is nothing but a succession of images of one of the finest slits which our best opticians are able to make.

You see, therefore, that our spectroscope depends first of all on Newton's work with the prism in 1675 , and on the fact which Newton found out incidentally, that it is important that the prism should be used at the angle of minimum deviation. We then get the slit added by Wollaston in $\mathrm{I} 8 \mathrm{I} 2$; then the collimating lens, added by Simms, in 1830 . In this way we have arrived at the spectroscope improved and modified as an instrument, until at last we get spectroscopes so arranged that the glass is of the finest possible material, the angle being the largest possible, the glass the densest possible, and the number of prisms as great as possible.

There are some other considerations connected with the manufacture of spectroscopes which it is hardly necessary I should bring before you, as they are rather more in the nature of detail than of general principles; but I must point out that where liquids are employed, it is absolutely essential that the temperature should be as equable as we can get it. A current of warm air in a room is quite sufficient to renỏer any spectrum obtained by these liquid prisms perfectly useless; hence, although their great dispersive power is of great value in some cases, where we want dispersion more than anything else, still, as a rule, we are limited for nearly all our researches to these dense glass prisms of great angle, to which I have already alluded. But there is another consideration of great importance which comes in here. If the angle of a prism be large, a ray of light travelling from one prism to another, enters the second at an extremely small angle, under which circumstances a large amount of light is reflected, but still it is not better to use a greater number of prisms of a smaller angle than a smaller number of a larger one. Again in spectroscopes of many prisms it is essential that there should be some arrangement by which each part of the spectrum should be observed with each prism at the angle of minimum deviation for that ray. This may be done in many ways, and the beam may be made to pass back ayain throush the prisms, thus doubling the amount of dispersion. On these points I shall have more to say prosently.

Another important consideration, besides the purity of the material, is the perfect figure oi the slit. You might imagine that the slit of a spectroscope was perfectly casy to make ; but, judging by the results of the manufacture, it is extremely difficult, for a perfect slit is still very rare, the best being made by Steinheil of Munich. Mr. Browning has suggested making the slit of a compound of gold, which will not rust, or be acted upon much by temperature, and which also will take a good figure without any very great difficulty.

(To be continued.)

NORMAN LOCKYER.

\section{NOTES}

THE Académie Royale de Belgique has elected Dr. Hooker "Membre associé." This has been done as their contribution to the Kew controversies. Prof. Monen, writing from Liege, is glad that Dr. Hooker has received "le plus haute distinction scientifique que notre pass peut conferer . . . dans une moment on vous (Dr. H.) soutenez une lutte vive et penible pour l'honneur de la botanique."

IN their desire to uphold the standari of medical teaching, the authorities of Charing Cross Hospital have committed an act which presents the appearance of an injustice. Not only have they not elected anyone to the vacant post of Demonstrator of Anatomy at their school, but they have sent the following announcement to each of the candidates:--" Resolved: That in the opinion of this Committee, the gentlemen who have offered themselves as candidates for the Demonstratorship of Anatomy have not had sufficient practical experience in teaching anatomy to justify the Committee in selecting any one of them." The Committee would, of course, have been perfectly warranted in 